\title{
THE PRIVATE DEMAND FOR INNOVATION: THE CASE OF EX - YU COUNTRIES
}

\author{
Slagjana Stojanovska² \\ Violeta Madzova ${ }^{3}$ \\ Biljana Gjozinska ${ }^{4}$
}

Received: February 26, 2018 / Revised: May 17, 2018 / Accepted: June 29, 2018

(C) Association of Economists and Managers of the Balkans, 2018

\begin{abstract}
In the era of high sophisticated technology, the innovation is recognized as a key driver towards better national competitiveness and economic growth, creating opportunities for better employment and better responding to global social challenges. At the company level however, innovation improves efficiency, boosts company productivity and provides numerous benefits to the consumers. Being identified as a key variable for the importance of demand for innovation, buyer sophistication signals the ability of buyers to select products and services based on performance rather than price. Furthermore, the companies witnessing more sophisticated domestic market are likely to sell products with higher quality and to better understand the customers' needs and how they perceive the value of the product.

This paper aims to provide a comparative analysis of private demand for innovation in selected ex-YU countries using the two key indicators: "buyer sophistication" and "sales of new-to-market and new-to-firm product innovations for the period 2011-2016. Although sharing the same sociopolitical and historical background, the analysis of these selected countries show significant discrepancies among their business leaders' assessments about the level of their customer demand for innovation and business sophistication.
\end{abstract}

Keywords: private demand, buyer sophistication, innovations, value, sales

\section{JEL Classification O31}

This paper was presented at the Second International Scientific Conference on Economics and Management - EMAN 2018, March 22 2018, Ljubljana, Slovenia, www.eman-conference.org

Slagjana Stojanovska

slagjana.stojanovska@fbe.edu.mk

Integrated Business Faculty, bul. 3-ta Makedonska brigade, 66A - , Skopje; Macedonia International Balkan University, Skopje, Macedonia

Integrated Business Faculty, bul. 3-ta Makedonska brigade, 66A - , Skopje; Macedonia 


\section{INTRODUCTION}

The consumer is the basic economic unit that determines the quantity and the types of the products and services that are purchased, or will be purchased. Hence, demand is determined by the individual, businesses or public consumers who have "the desire or preference to purchase an affordable product or service" (NESTA, 2010). The preferences are a way of characterizing consumers' relative desire to choose one from possible market offers in any given interaction (Australian Government, 2012). Therefore, demand expresses a willingness to pay a certain price for the satisfaction of a need or want (Mowery and Rosemberg, 1979). According to Kotler (2002), the customer value is define as "customer's perception about the benefits received from using a product (service) relative to the cost and risks associated with acquiring it". It simple expresses a ratio between "what the customer gets" and "what the consumer gives", understanding that the customer gets benefits (functional benefits + emotional benefits) and assumes costs (monetary costs + time costs + energy costs + psychic costs) (Kotler, 2002). Following Kotler's logic, the company can increase the value of the customer offering by (1) raising benefits, (2) reducing costs, (3) raising benefits and reducing costs, (4) raising benefits by more than the raise in costs, or (5) lowering benefits by less than the reduction in costs.

Furthermore, it can be noticed that one key variable for the importance of demand for innovation is the buyer sophistication. This signals "....the ability of buyers to select products based on performance rather than price and, thus their willingness to purchase innovative products and services and to bear their higher costs at the beginning of the life cycle (Edler, 2011). This demand factor can shape innovation activity in two major ways (OECD, 2005): (1) for the development of new products, as firms modify and differentiate products to increase sales and market share; and (2) for the improvement of the production and supply processes in order to reduce costs and lower prices.

Innovation is the first attempt to put an idea into practice. This is distinct from invention, which is the first occurrence of an idea. Many definitions of innovation, including the OECD-Eurostat definition, explaining that innovation covers five areas (Fagerberg, 2005): product innovation, process innovation, marketing innovation, input innovation, and organizational innovation. Within each type of innovation, there are three levels of innovation (NESTA, 2010): incremental, radical and transformational. The incremental innovation refers of small continuous improvements that cause relatively little disruption, e.g. a new invoicing system; the radical innovation refers of new to the market or firm, often disruptive to the industry, discontinuous, e.g. a new product for sale or a new business model such as home delivery for a retailer and transformational innovation refers of new to the world, rare but big innovations that cut across all industries, e.g. the World Wide Web. The minimum requirement for an innovation is that ,"the product, process, marketing method or organizational method must be new (or significantly improved) to the firm" (Fagerberg, 2005) or other user and introduced on a market or that the new processes are used in production

It is important to note that the innovations must be commercialized, that is, launched on the market, or in other ways widely diffused to customers on a large scale in the economy or society. Criteria for success can include market share, number of sales, profit made, diffusion rate, beating competitors, or changes in customer's behaviour. But, the high degrees of Buyer sophistication could explain higher shares of innovative sales. 
In this paper, we are analyzing the demand for innovation in context of the selected ex-YU countries $^{5}$ such as Croatia, Slovenia, Macedonia and Serbia during 2011 to 2016. These countries have a common past of about 45 years when they shared same market in the within of former Yugoslavia. For cultural or historical reasons, buyers may be more demanding for innovation in some countries than in others. Therefore, in this article, we explore the following questions:

- Do the customers in ex-YU countries differ in their degree of Buyer sophistication?

- How many sales of innovative products are realized by the companies in ex-YU countries?

- Do the business managers from ex-YU countries make a good assessment of private demand for innovation and in which ex-YU country it better is doing?

- In that group of adopter for now product belong the buyers from ex-YU countries?

In the next two sections, we present the methodological framework and date and the analysis based on the findings. At the end is the conclusion.

\section{METHODOLOGY AND DATA}

A better understanding of the consumer demand for innovation influence on organizational activities, but the companies have limited understanding about the consumers' preferences or the sophistication of the customers. Hence, our starting point is that the business leaders' understanding related to the buyers' sophistication, influences towards increasing sales of innovation product/services. Further, we assume that "higher degrees of buyer sophistication can explain higher shares of innovative sales" (Hollanders and Es-Sadki, 2017) in context of the ex-Yu countries during 2011 to 2016. In order to analyze these starting points, we need effective ways to measure it. Most aggregate, publicly available data focus on innovation is the European Innovation Scoreboard (EIS) that includes different indicators to measure and compare relative efficiency of the performance of country's innovation systems. The EIS data is from different data sources such as the Community Innovation Survey, EUROSTAT and other internationally sources such as the OECD and the United Nations. Second source, which characterize demand conditions across different countries is the Global Competitiveness Report (GCR) by the World Economic Forum (WEF). The GCR data is largely based on surveys of business leaders who give their subjective assessment on a whole series of demand side variables.

For the issues in this paper we used two indicators which characterize the demand for innovation by above two source. The first indicator, "Bayer sophistication" is included in the Executive Opinion Survey of the World Economic Forum (WEF) (2011-2016) based on surveys of business leaders who give their subjective assessment of this demand variable. While this is not a hard indication, it nevertheless shows how business lenders in the countries perceive the situation, and those perceptions are the basis for decision making for innovation activities. The degree of Buyer sophistication measures, on a scale from 1 (low) to 7 (high), the degree of the preferences of individual consumers for innovative products, whether buyers focus more on price or quality of products and services. The second indicator, "Sales of new-to-market and new-to-firm product innovations (measures as \% of turnover)" is employed by the European Innovation Scoreboard (EIS) in order to takes the customers purchase of innovation into account. The EIS indicator "Sales of new-to-market and new-to-firm product innovations" (EISI. SNM\&NFP innovation) has normalized score from 0 ( $\mathrm{min})$ to 1 ( $\max )$.

\footnotetext{
${ }^{5}$ The former Yugoslavia included Slovenia, Croatia, Serbia, Macedonia, Montenegro, Bosnia and Hercegovina, but for the last two countries the EIS data is not collected.
} 
In order the two indicators scores to be comparable they should to have same value. So, we adjust the score of the GCR indicator "Buyer sophistication" (GCRI. BS) of each ex-Yu countries in the following way: the GCRI.BS score is divided by the number 7 which is the maximum of the best GCR score. For example, the GCRI. BS score of Macedonia for 2016 is 2.9 (on scale from 1 to 7), but after adjusting its score is 0,41 (on a scale from 0 to 1 ).

The comparative analysis between the indicators is based on the average score obtained by of the four scores of the ex-YU countries of given indicator. Furthermore, as "people differ greatly in their readiness to try new products .... and ....can be classified into the adopter categories after a slow start, an increasing number of people adopt the new product” (Rogers, 2003), ,in this paper we classify buyers of the ex-YU countries into the three adopter categories: high adopters, moderate adopters and low adopters buyers. So, according to the indicators "Sales of new-to-market and new-to-firm product innovations (measures as \% of turnover)" the countries with five-years average score above of the five-years average score by all ex-YU countries indicates have high adopters buyers. Those countries whose the five-years average score scores, for same indicators, is equal to the five-years average score by all ex-YU countries have moderate adopter buyers. In the three group are countries with the five-year average score below from the five-year average score by all ex-YU countries, which have low adopter buyers.

\section{ANALYSIS}

For first question, Do the customers in ex-YU countries differ in their degree of Buyer sophistication, we look at the results presented in Figure 1. The figure shows overall comparison of the CGR's indicator Bayer sophistication (CGRI. BS) with customized scores (from min=0 to $\max =1$ ) between the ex-YU countries relative to the average for ex-YU countries that is 0,38 in 2011, to 0,40 in 2016. Hence, it can noted than the CGRI. BS scores are the highest of Slovenia compared to the average for ex-YU countries and in relation to the individual scores of other exYU countries. Contrary to this, the lowest degree of buyer sophistication has Serbia for all years. The Macedonian buyer sophistication go up in 2014, then fell down in 2015, while in 2016 the degree of buyer sophistication again grow. In Croatia from 2013 has trend of decreasing. from 2015 has trend of increasing the degree of, but are lower in relation to Slovenia

This means that buyers from Macedonia and Croatia, but especially from Serbia are not very prone or able to buy innovation products or leading edge technology. Thus, the pre-conditions for innovations to be absorbed in the market are challenging. "One reason for lower buyer sophistication can be limits of disposable income of private consumers" (Edler, 2009). Besides that, Edler (2009) suggests demand policies that target awareness, attitudes and skills of buyers, and on other hand to influence the innovation culture in the market, making buyers more risk taking, aware of innovations and empower them to use them. 
Figure 1: Differences between of ex-YU countries at Buyer sophistication

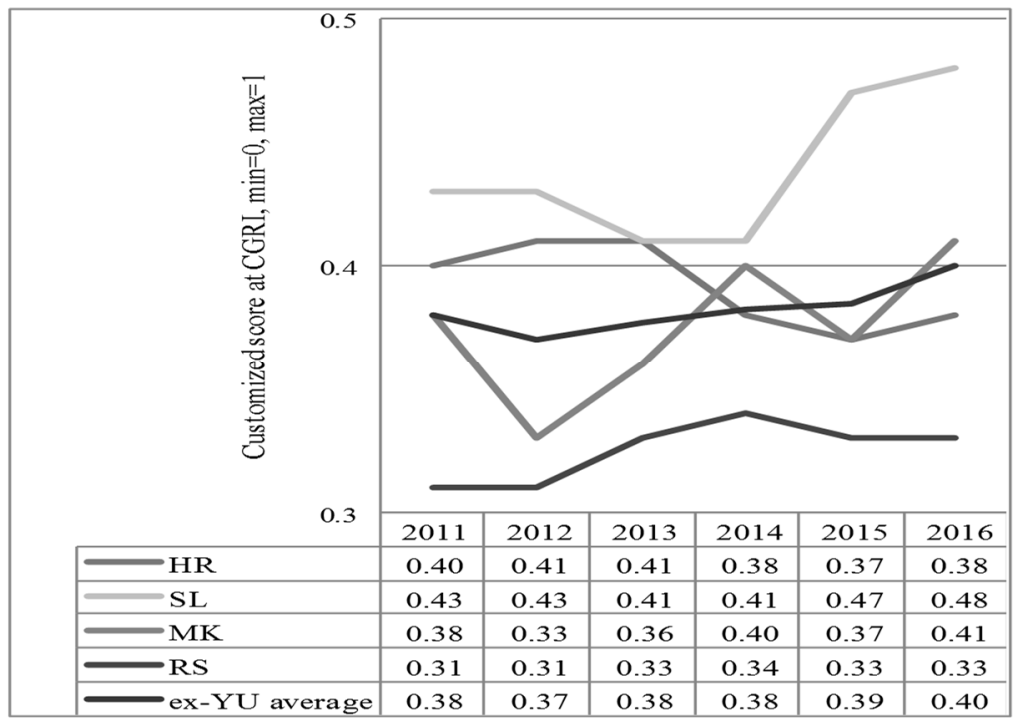

Source: author's calculations based on of the GCR data

As it was previously mentioned, the second question, How many sales of innovative products are realized by the companies in ex-YU countries, we consider through EIS indicators "Sales of newto-market and new-to-firm product innovations" (EISI. SNM\&NFP innovation) (see Figure 2).

Figure 2: Differences between of ex-YU countries of sales of innovations

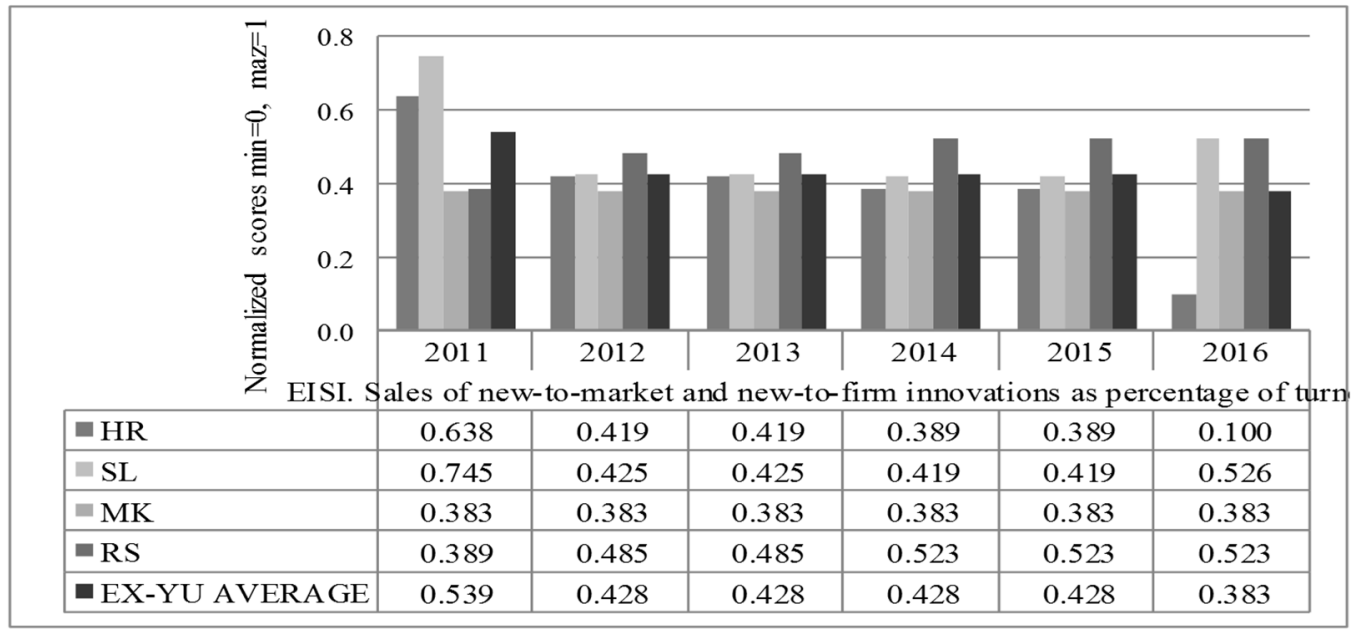

Source: author's calculations based on of the EIS data

From Figure 2, it can be noted that Serbia from 2012 to 2016 achieves the highest level of sales in relation to average at ex-Yu countries, followed by Slovenia. Macedonia has an unchanging constant for all five years, while Croatia has a serious fall in the sales of innovation in 2016.

Finally, for the third question (see Figure 3), Do the business managers from ex-YU countries make a good assessment of private demand and in which ex-YU country it better is doing, we doing a comparative analysis using above two indicators (GCI. BS and EISI. SNM\&NFPI). 
Figure 3: Assessment of private demand for innovation by business leaders
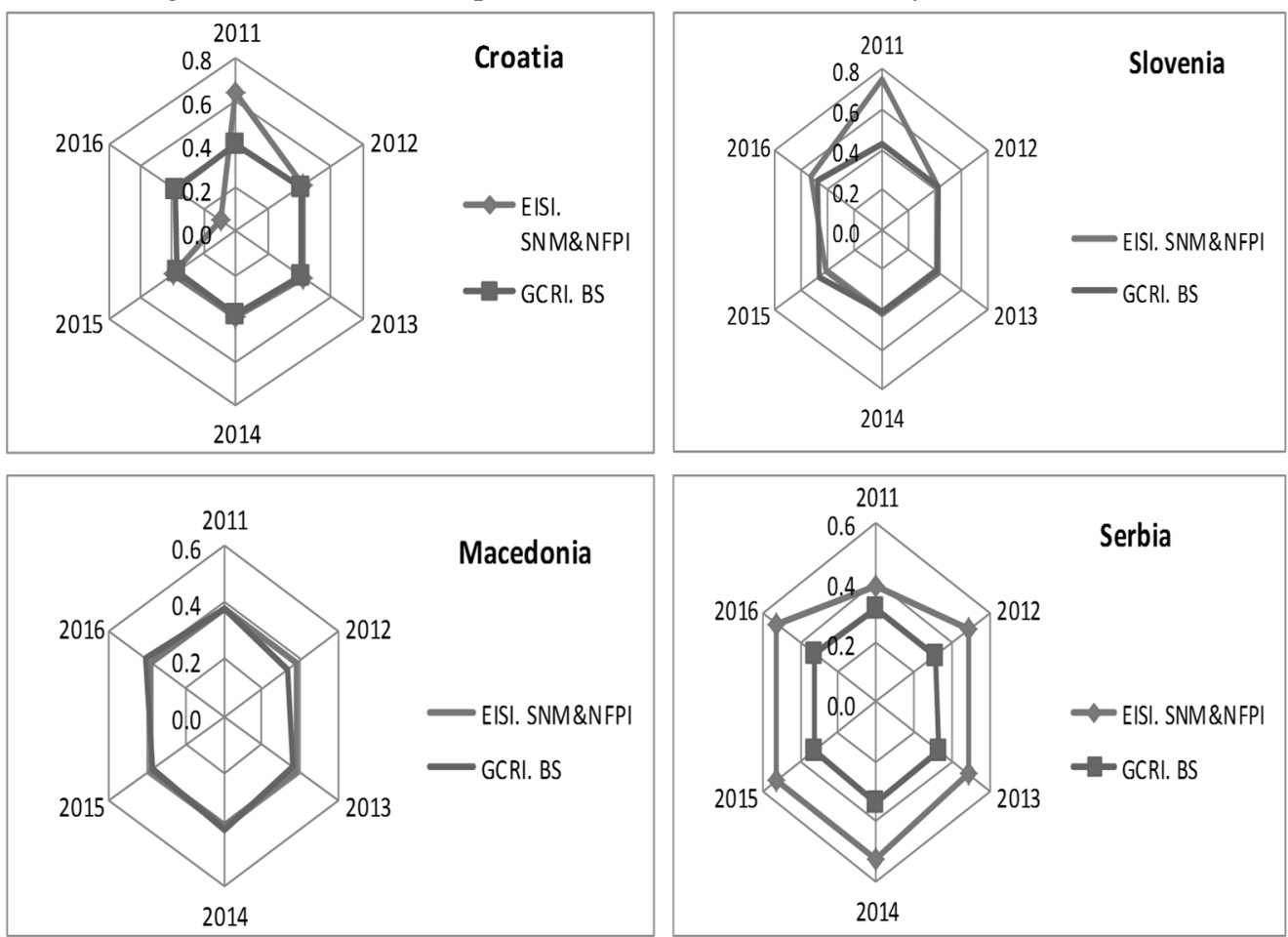

Source: author's calculations based on of the GCR data and EIS data

As the Figure 3 presents, Serbia has an obvious gap between the two indicators during 2011 to 2016, much sales of innovation in relation the assessment at low buyer sophistication. This means that the business leaders in Serbia think that most buyers are unwilling to pay for innovative products while on other hand its companies achieve high sales of innovation. This contradiction shows that business leaders in Serbia need better to understand customers' preferences and it to incorporate into their business strategies and innovative activities, in order to increase profits as a result of a greater offer with innovative products.

Similarly, the business leaders in Croatia (see Figure 3) should have a better understanding of the concept buyer sophistication, because they opposite from their colleagues in Serbia higher assess its buyers in relation low achieved sales of innovation in 2016. Fall on the sale for innovation show that the buyers in Croatia in 2016 made purchasing decisions for innovation based on the lowest price.

The business leaders in Slovenia and Macedonia show a greater understanding of purchasing decisions for innovation of its buyers because sales of innovation and it's assess for the sophistication of buyer is equal. 
Figure 4: The best private demand for innovation during 2011 to 2016

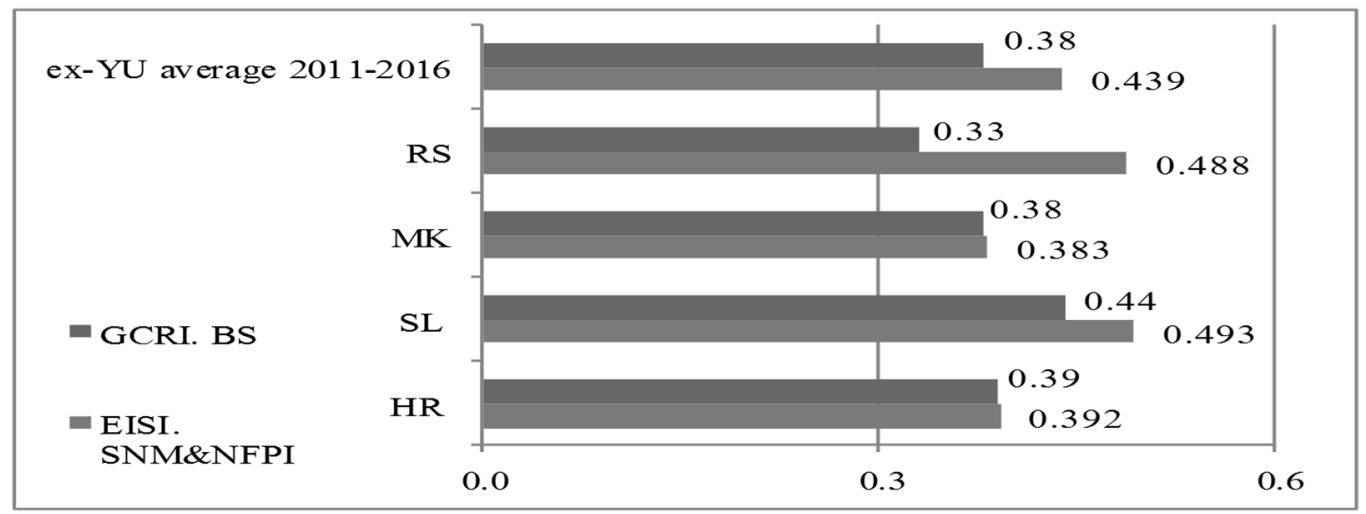

Source: own compilation based on of the GCR data and EIS data

Finally, we do a comparative analysis between the ex-YU countries, based on the amount of adoption of new products by buyers, in order to classify them in one of the three earlier mentioned groups: high adopters, moderate adopters and low adopters buyers. For this purpose, we used the five-year average (2011-2016) scores of the two indicators (GCI. BS and EISI. SNM\&NFPI) in relation of the five-year average score of ex-Yu countries (2011-2016). Figure 4 provides the exYu countries' scores of those indicators. From the observed scores of the ex-YU countries Slovenia have the highest single value for the two the indicators, followed by Serbia that indicate that its buyers belong in the group high adopter of now product. Unlike them, the scores of Macedonia and Croatia are near to the five-year average score of ex-Yu countries that means that their buyers are in the group of moderate adopters.

Overall, this finding calls for change of demander's behaviour for innovation and transforming the market into a desirable direction, such as adopter of innovation product. For example, demand oriented policies which would have to influence the innovation culture in the market of each exYU countries, making buyers more risk taking, aware of innovations and encourage to adopter now product and to use it. Work done by Rothwell (2007) found that a majority of successful innovations where in fact reactions to perceived changes in demand preferences rather than due to radical developments on the technology side (Elder, 2013). Accordingly, innovation failures were often due to a misperception of what the market is ready and willing to accept, and a lack in sound marketing before and after innovations were generated. By taking advantage of opportunities to involve users early in the innovation process organisations can gain advanced insight from customers and maximize their competitive advantage (NESTA, 2010).

\section{CONCLUSION}

It is important to note that the innovations must be commercialized, that is, launched on the market, or in other ways widely diffused to customers on a large scale in the economy or society. Criteria for success can include market share, number of sales, profit made, diffusion rate, beating competitors, or changes in customer's behaviour. But, the high degrees of Buyer sophistication could explain higher shares of innovative sales.

Overall, the paper's finding calls for change of demanders' behaviour for innovation and transforming the market into a desirable direction, such as adoption of innovation product. For example, demand oriented policies which would have to influence the innovation culture in the market of each ex-YU countries, making buyers more risk taking, aware of innovations and 
encourage to adopter now product and to use it. Accordingly, the innovation failures were often due to a misperception of what the market is ready and willing to accept, and a lack in sound marketing before and after innovations were generated. By taking advantage of opportunities to involve users early in the innovation process organizations can gain advanced insight from customers and maximize their competitive advantage.

\section{REFERENCES}

Australian Government, Office of Best Practice Regulation, Influencing Consumer Behaviour: Improving Regulatory Design, 18th December 2012, http://ris.pmc.gov.au/2012/12/18/obprresearch-paper-influencing-consumer-behaviour-improving-regulatory-design

Edler, J. (2011). Innovation in EU CEE: the role of demand based policy, book Challenges for European Innovation Policy: Cohesion and Excellence from a Schumpeterion Perspective (edited by Slavko Radosevic and Ana Kaderabkova), Edward Elgar Publishing

Edler. J. (2009). Demand Policies for Innovation in EU CEE Countries, Manchester Business School Working Paper No 579

Elder, J. (2013). Review of Policy Measures to Stimulate Private Demand for Innovation. Concepts and Effects, Nesta Working Paper 13/13

European Commission, European Innovation Scoreboard (various years). Available at: http://ec.europa.eu/DocsRoom/documens/24141. Accessed on 14.02.2018

Fagerberg, J. (2005). Innovation: A guide to the literature. In Fagerberg, J., Mowery, D.C. and Nelson.

Hollanders, H., Es-Sadki, N. (2017). European Innovation Scoreboard 2017 - Methodology Report, European Commission.

Kotler, P. (2002). Marketing Management Millenium Edition, 10th ed, Prentice-Hall, Inc.

Mowery, D., Rosemberg, N. (1979). The influence of market demand upon innovation: A critical review of some recent empirical studies. Research Policy, 8 (2), 102-153

NESTA, (2010). Demand and innovation: How customer preferences shape the innovation process. NESTA/The Work Foundation Working Paper. London NESTA.

OECD (2005). The Measurement of Scientific and Technological Activities; Oslo Manual, Guidelines for Collecting and Interpreting Innovation Data, 3rd Edition. OECD, Statistical Office of the European Communities, Luxembourg.

Rogers, E. M. (2003). Diffusion of innovations (Fifth Edition). New York: Free Press

Rothwell, R. (2007). The characteristics of successful innovators and technically progressive firms. $R \& D$ Management, 7 (3), 191-206

World Economic Forum, the Global Competitiveness Report (publications from 2011 to 2016) 